\title{
Luteolin attenuates migration and invasion of lung cancer cells via suppressing focal adhesion kinase and non-receptor tyrosine kinase signaling pathway
}

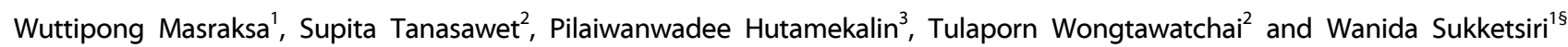 \\ ${ }^{1}$ Department of Pharmacology, Faculty of Science, Prince of Songkla University, Songkhla, 90110, Thailand \\ ${ }^{2}$ Department of Anatomy, Faculty of Science, Prince of Songkla University, Songkhla, 90110, Thailand \\ ${ }^{3}$ Department of Physiology, Faculty of Science, Prince of Songkla University, Songkhla, 90110, Thailand
}

BACKGROUND/OBJECTIVES: Non-small cell lung cancer is mostly recognized among other types of lung cancer with a poor prognosis by cause of chemotherapeutic resistance and increased metastasis. Luteolin has been found to decrease cell metastasis. However, its underlying mechanisms remain unresolved. The objective of this study was to examine the effect (and its mechanism) of luteolin on the migration and invasion of human non-small cell lung cancer A549 cells.

MATERIALS/METHODS: Cell viability was investigated by 3-(4,5-dimethylthiazol-2-yl)-2,5-diphenyltetrazolium bromide assay. Wound healing and transwell assays were evaluated to assess migration and invasion, respectively. Western blot analysis and immunofluorescence were further performed to investigate the role of luteolin and its mechanisms of action.

RESULTS: Administration with up to $40 \mu \mathrm{M}$ luteolin showed no cytotoxic activity on lung cancer A549 cells or non-cancer MRC-5 cells. Additionally, luteolin at 20-40 $\mathrm{MM}$ significantly suppressed A549 cells' migration, invasion, and the formation of filopodia in a concentration-dependent manner at $24 \mathrm{~h}$. This is similar with western blot analysis, which revealed diminished the phosphorylated focal adhesion kinase (pFAK), phosphorylated non-receptor tyrosine kinase (pSrc), Ras-related C3 botulinum toxin substrate 1 (Rac1), cell division control protein 42 (Cdc42), and Ras homolog gene family member A (RhoA) expression levels. CONCLUSIONS: Overall, our data indicate that luteolin plays a role in controlling lung cancer cells' migration and invasion via Src/FAK and its downstream Rac1, Cdc42, and RhoA pathways. Luteolin might be considered a promising candidate for suppressing invasion and metastasis of lung cancer cells.

Nutrition Research and Practice 2020;14(2):127-133; https://doi.org/10.4162/nrp.2020.14.2.127; plSSN 1976-1457 elSSN 2005-6168

Keywords: Adenocarcinoma, flavonoids, luteolin, A549 cell

\section{INTRODUCTION}

Lung cancer is the third ranking cause of cancer-associated deaths worldwide, after breast and prostate cancer [1]. Epidemiological research revealed that non-small cell lung cancer (NSCLC) is the dominant type (80\%) of lung cancer, and its prognosis remains notably poor with a 5-year survival rate below 20\% [2]. Ongoing therapies for NSCLC, including surgery, radiotherapy and chemotherapy, have a limited effect on patient survival, and the associated high toxicities include neutropenia, peripheral neuropathy, nausea and vomiting, and nephrotoxicity [3]. Therefore, novel cancer therapeutic agents with high efficacy and low toxicity or less severe side effects are desired.

Metastasis is a multistep complex process, in which local invasion of the primary tumor is important for the initiation of metastasis. The machinery of cell migration is associated with several complicated steps asociating the stimulation of various important regulatory proteins. Rho GTPase proteins, such as Ras-related C3 botulinum toxin substrate 1 (Rac1) and cell division control protein 42 (Cdc42), which was shown to trigger actin polymerization and reorganization, occurring in the filopodia and the lamellipodia protrusion $[4,5]$. Simultaneously, the active structure of Ras homolog gene family, member A (RhoA) activates the actin-myosin shrinkage [6]. A previous study has established that Rho GTPase family migratory proteins are stimulated via the focal adhesion kinase (FAK) and a nonreceptor tyrosine kinase (Src) pathways [7]. Besides, FAK and Src activation has been established in highly metastatic cancer cells [8-10]. It has been revealed that lung cancer cells' migration and invasion are mediated due to the stimulation of FAK and Src pathways [11]. Accordingly, inhibiting these proteins'

\footnotetext{
The study was supported by the grant from the General Project and Invention of Prince of Songkla University (no. SCI610456S) and Faculty of Science Research Fund (Contract no. 1-2560-02-004), Prince of Songkla University, Songkhla, Thailand.

${ }^{\S}$ Corresponding Author: Wanida Sukketsiri, Tel. 66-7428-8171, Fax. 66-7428-8171, Email. wanida.su@psu.ac.th

Received: July 24, 2019, Revised: August 16, 2019, Accepted: September 17, 2019

This is an Open Access article distributed under the terms of the Creative Commons Attribution Non-Commercial License (http://creativecommons.org/licenses/by-nc/3.0/) which permits unrestricted non-commercial use, distribution, and reproduction in any medium, provided the original work is properly cited.
} 
<smiles></smiles>

Fig. 1. Chemical structure of luteolin

activities block the mobility and metastasis of numerous cancer cells $[12,13]$.

Luteolin (3',4',5,7-tetrahydroxyflavone; Fig. 1), a natural flavonoid compound, is generally found at high concentration in fruits, vegetables and medicinal herbs [14]. Luteolin obtains various pharmacological effects such as anti-oxidant, anti-cancer, antiinflammation, immune regulation and cardioprotection [15-17]. Many studies have revealed that luteolin has anti-tumor activity against various types of cancer [18-20]. A number of studies have found that luteolin has a potent effect on human NSCLC A549 cell proliferation by activating cell death and inhibiting cell migration [21,22]. Previous report revealed that luteolin inhibit cancer cell migration is correlated with suppression of the activation of phosphorylated insulin-like growth factor-1 receptor ( $p$-IGF-1R), phosphoinositide 3-kinase (PI3K), protein kinase $B$ (Akt) and mammalian target of rapamycin (mTOR) signaling pathway [23]. Nevertheless, the mechanisms of action of luteolin in suppressing cancer cells' migration and invasion remain unresolved. Especially, the expression of FAK, Src and Rho GTPase proteins, such as Rac1, Cdc42 and RhoA, in human lung cancer cells has not been identified. Therefore, this study aimed to investigate whether luteolin is able to restrain cell migration and invasion by human NSCLC A549 cells; and whether this occurs by suppressing the FAK, Src as well as Rac1, Cdc42 and RhoA pathways, relevant to filopodia formation.

\section{MATERIALS AND METHODS}

\section{Chemicals and reagents}

Luteolin, dimethysulfoxide (DMSO), 3-(4,5-Dimethylthiazol-2yl)-2,5-diphenyltetrazolium bromide (MTT), bovine serum albumin (BSA), phenylmethylsulfonyl fluoride, and protease inhibitor cocktail were obtained from Sigma Chemical, Inc. (St. Louis, MO, USA). Antibodies for FAK (Santa Cruz Biotechnology, CA, USA), pFAK (Santa Cruz Biotechnology, CA, USA), Src (Abcam, Cambridge, UK), pSrc (Abcam, Cambridge, UK), Rac1 (Merck, Kenilworth, USA), RhoA (Abcam, Cambridge, UK), Cdc42 (Merck, Kenilworth, USA), $\beta$-actin (Thermo Scienetific, Waltham, MA, USA), and peroxidase conjugated secondary antibodies (Thermo Scienetific, Waltham, MA, USA) were purchased. Lysis buffer and chemiluminescent substrate were obtained from Thermo Scientific (Supersignal West Pico; Pierce, USA).
Cell cultures

MRC-5 human lung fibroblast cells and A549 human lung carcinoma cells were received from the CLS cell lines service (Eppelheim, Germany). The lung cancer A549 cells were grown in DMEM/Ham-F12 medium, whereas MRC-5 cells were cultured in DMEM medium. Both of cell types were kept in a $5 \% \mathrm{CO}_{2}$ humidified incubator at $37^{\circ} \mathrm{C}$. The media were enriched with $10 \%$ fetal bovine serum (FBS), $2 \mathrm{mM}$ L-glutamine, $100 \mathrm{IU} / \mathrm{mL}$ penicillin, and $100 \mu \mathrm{g} / \mathrm{mL}$ streptomycin (Gibco, MD, USA). Both types of cells were sub-cultured using trypsin-EDTA at $80-90 \%$ confluence.

\section{Cell viability assay}

MTT colorimetric assay was used for examination of cell viability. A549 cells and MRC-5 cells were seeded at $1 \times 10^{4}$ cells/well and incubated for $24 \mathrm{~h}$ in a 96-well plate for cell attachment. Both types of cells were then administered with various concentrations of luteolin $(0-80 \mu \mathrm{M})$ for $24 \mathrm{~h}$ in order to investigate cell viability. Following the $24 \mathrm{~h}$ of luteolin administration, the medium was discarded and the cells were incubated with MTT solution for $2 \mathrm{~h}$ at $37^{\circ} \mathrm{C}$. Formazan product was solubilized with DMSO, and the intensity was assessed using a microplate reader at $570 \mathrm{~nm}$ (Biotek, Winooski, VT, USA). The experimental results are presented as the percentage of cell viability comparative to the non treatment control.

\section{Nuclear staining assay}

A549 cells $\left(5 \times 10^{4}\right.$ cells/well) were grown in 24-well plates, and incubated overnight. A549 cells were administered with luteolin at different concentrations $(0,10,20$ and $40 \mu \mathrm{M})$ at $37^{\circ} \mathrm{C}$ for $24 \mathrm{~h}$. Hoechst $33342(10 \mu \mathrm{g} / \mathrm{mL})$ was applied to the cells for $30 \mathrm{~min}$ at $37^{\circ} \mathrm{C}$, as described previously [24]. The apoptotic cells, which have the chromatin condensation and fragmented nuclei, were observed by utilizing a fluorescence microscope (Olympus IX73; 20X) supplied with a DP73 digital camera system (Olympus, Tokyo, Japan).

\section{Wound healing assay}

Cells were grown until they reached $90-95 \%$ confluence in 6-well plates. A sterile $200 \mu \mathrm{L}$ pipette tip was applied to make a cross-shaped wound. Then, the cells were gently rinsed with PBS. Subsequently, the cells were cultivated for 0,24 and 48 h. Cells that migrated to the wounded area were imaged. The percentage of wound closure was also evaluated.

\section{Cell invasion assay}

A trans-well chamber (Corning, NY, USA) was used for an invasion assay. Prior to seeding the cells in the upper chamber, the membrane ( $8 \mu \mathrm{m}$ pore size) was applied with matrigel $(0.5 \%)$ for $12 \mathrm{~h}$ at $37^{\circ} \mathrm{C}$. After $24 \mathrm{~h}$, A549 cells $\left(5 \times 10^{4}\right.$ cells/well) were grown in the upper chamber supplied with serum-free medium. The lower chamber was supplied with complete medium containing FBS (10\%). After that, the unpenetrated cells were lightly detached with a cotton swab in the upper chamber, whereas the penetrated cells that had invaded the lower compartment were fixed with paraformaldehyde (PFA) (4\%) for $10 \mathrm{~min}$ and stained with Hoechst $33342(10 \mu \mathrm{g} / \mathrm{mL})$ for $30 \mathrm{~min}$ $(\mathrm{N}=4)$. The cells were observed and photographed using a 
fluorescence microscope (Olympus IX73; 20X). Finally, the invading cells were counted as (the number of invaded cells treated with luteolin/the number of invaded cells of non-treated cells) $\times 100$.

\section{Filopodia evaluation assay}

Filopodia was evaluated by phalloidin-rhodamine staining assay as reported previously [25]. Phalloidin rhodamine was applied to specific binding with the polymerized form of actin (F-actin) in the cells. Briefly, luteolin-treated A549 cells were fixed with 4\% PFA and permeabilized for $5 \mathrm{~min}$ with $0.1 \%$ Triton- $X$ in PBS. Subsequently, the cells were washed and blocked for non-specific binding with BSA $(0.2 \%)$ for $1 \mathrm{~h}$, followed by incubation with a phalloidin rhodamine for $30 \mathrm{~min}$. Cell morphological alterations were observed and photographed using a fluorescence microscope (Olympus IX73; 40X). The filopodia counts are reported as (number of filopodia/number of cells) $\times 100$.

\section{Western blot analysis}

After treatment with luteolin to A549 cells, lysis buffer and protease inhibitor cocktail were applied for $30 \mathrm{~min}$ on ice. The cellular lysates were collected and the content of protein was detected using a Bradford reagent (Bio-Rad, USA). The $75 \mu \mathrm{g}$ of protein from each sample were separated by sodium dodecyl sulfate polyacrylamide gel electrophoresis and moved to nitrocellulose membranes $(0.45 \mu \mathrm{M}$, Merck). The membranes were blocked with blocking solution for $2 \mathrm{~h}$, and were then applied with the appropriate primary antibodies overnight at $4^{\circ} \mathrm{C}$. Then, the membranes were washed and incubated with horseradish peroxidase-linked secondary antibodies for $1 \mathrm{~h}$ at room temperature. Eventually, the protein bands were evaluated using an enhanced chemiluminescence substrate.

\section{Statistical analysis}

Experimental data of four independent experiments are displayed as mean \pm standard error of the mean (SEM). The data analysis was carried out by R program (R Core Team, 2014) ANOVA (analysis of variance), followed by individual comparisons with Tukey's post-hoc test, was performed to analyze differences between multiple groups. Statistical significance required $P<$ 0.05 .

\section{RESULTS}

Effect of luteolin on cell viability in human lung cancer A549 cells

To determine an appropriate dose of luteolin for use in further experiments, we determined the cell viability of A549 cells treated with luteolin. The cells were administered with luteolin at different dosages $(0-80 \mu \mathrm{M})$ for $24 \mathrm{~h}$ and cell viability was then investigated. Fig. 2A shows that significant cytotoxic effects of luteolin were found only at the highest $80 \mu \mathrm{M}$ concentration, whereas it did not affect normal MRC-5 lung fibroblasts. Morphological examination of cell death after treatment with luteolin was done by both phase contrast microscopy and nuclei staining with Hoechst. Phase contrast microscopy demonstrated that luteolin induced A549 cell deaths in comparison to the untreated control (Fig. 2B). Distinctive morphological alterations, including the loss of cell processes and cell contact, more rounded morphology, and reduction of viable cells were observed with $40 \mu \mathrm{M}$ luteolin treatments. In addition, nuclei staining indicated that luteolin at $0-20 \mu \mathrm{M}$ did not induce apoptosis of cells. However, $40 \mu \mathrm{M}$ luteolin treatments significantly induced apoptotic cells, called by condensed and/or fragmented nuclei (Fig. $2 \mathrm{~B}$ and $2 \mathrm{C}$ ).

Luteolin attenuates migration and invasion of lung cancer A549 cells

Wound healing assay was carried out to evaluate the effects of luteolin on lung cancer cell migration. A549 cells were administered with luteolin at the concentrations $0,10,20$ and $40 \mu \mathrm{M}$ for 0,24 and $48 \mathrm{~h}$. Fig. $3 \mathrm{~A}$ and $3 \mathrm{~B}$ showed that luteolin at the concentrations of 20 and $40 \mu \mathrm{M}$ significantly suppressed

(A)

\begin{tabular}{c|c|c|c|c|c|c|c|c}
\hline $\begin{array}{c}\text { Luteolin } \\
(\mu \mathrm{M})\end{array}$ & 0 & 5 & 10 & 20 & 40 & 50 & 80 & $\mathrm{IC}_{50}$ \\
\hline A549 & $100.00 \pm 0.00$ & $101.05 \pm 5.92$ & $92.97 \pm 1.50$ & $91.53 \pm 2.21$ & $86.91 \pm 4.52$ & $85.49 \pm 1.37$ & $48.85 \pm 0.18^{*}$ & 78.86 \\
\hline MRC5 & $100.00 \pm 0.00$ & $102.03 \pm 6.86$ & $99.23 \pm 8.69$ & $97.82 \pm 6.26$ & $97.48 \pm 4.23$ & $97.68 \pm 4.29$ & $94.17 \pm 2.51$ & $>80$ \\
\hline
\end{tabular}

(B)
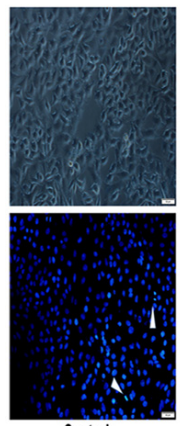

Control
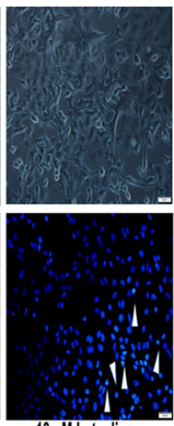

$10 \mu$ L Luteolin
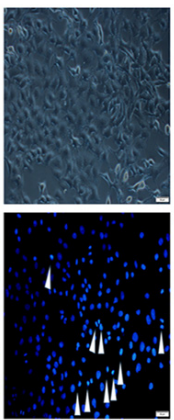

$20 \mu M$ Luteolin
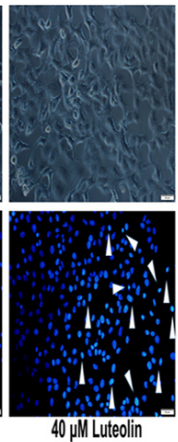

(C)

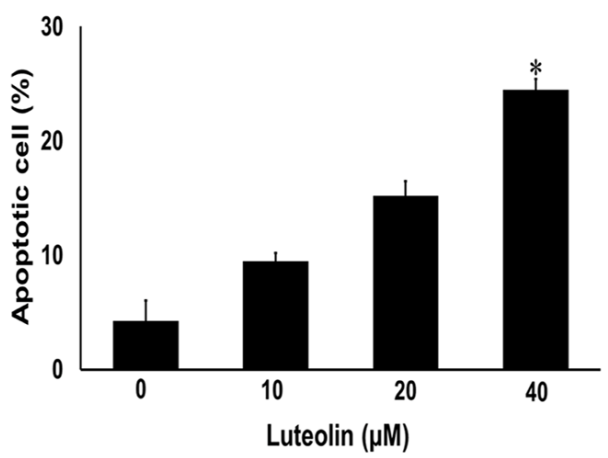

Fig. 2. Cytotoxic activity of luteolin against A549 cells. (A) 3-(4,5-Dimethylthiazol-2-yl)-2,5-diphenyltetrazolium bromide (MTT) assay after 24 h treatment. (B) Phase contrast microscopy and Hoechst 33342 staining after $24 \mathrm{~h}$ treatment (scale bar $=100 \mu \mathrm{m})$. White arrowheads indicate the apoptotic cells. (C) The number of apoptotic cells. Data are shown as mean \pm SEM from four independent experiments. ${ }^{*} P<0.001$ versus the control. 
(A)

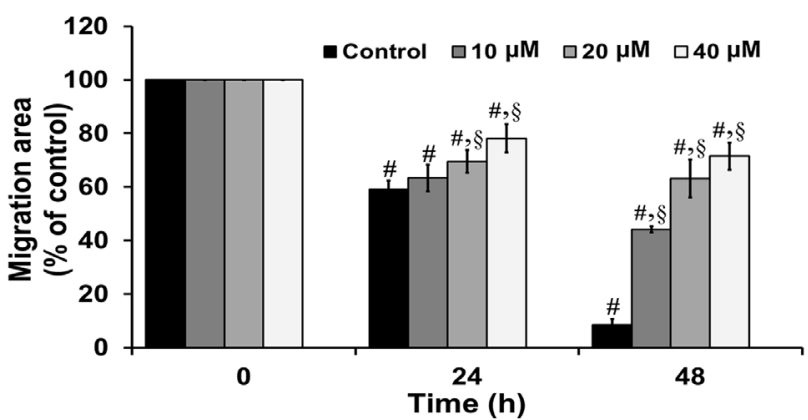

(B)

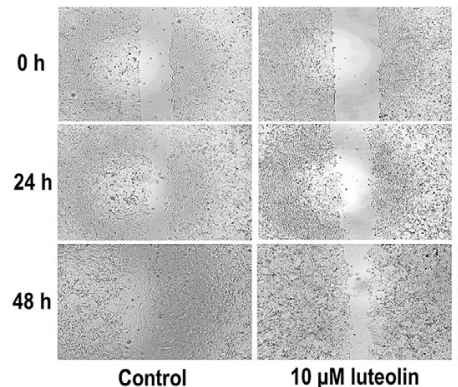

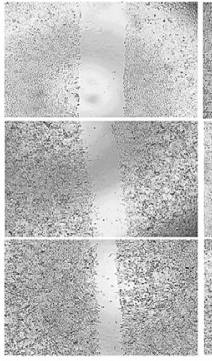

$20 \mu \mathrm{M}$ luteolin

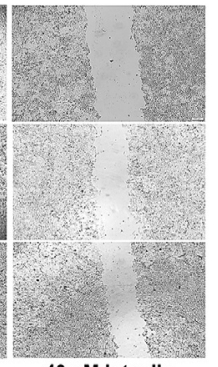

$40 \mu$ M luteolin

Fig. 3. Luteolin inhibits lung cancer cell migration. (A) The migration into wound area was determined from comparison to the control, (B) The cell migration was visualized via phase contrast microscopy (scale bar $=100 \mu \mathrm{m}$ ). Data are expressed as mean $\pm \mathrm{SEM}$ from four independent experiments. The differences between groups were evaluated by one-way ANOVA. ${ }^{\S} P<0.01$ compared to control. ${ }^{\#} P<0.01$ compared to time 0 .

(A)

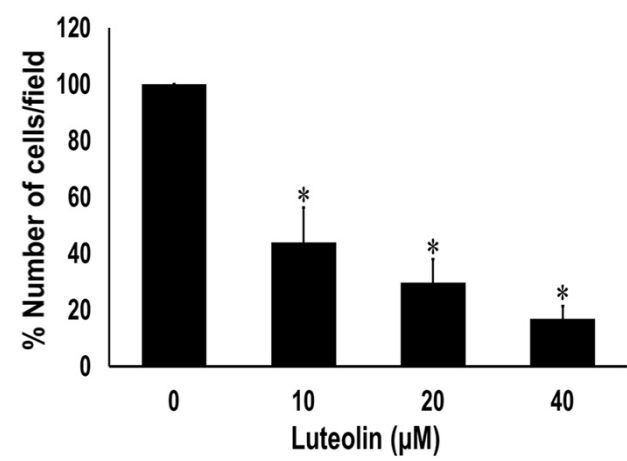

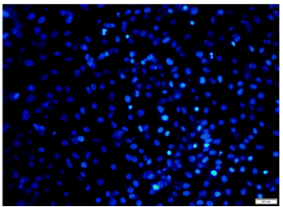

Control

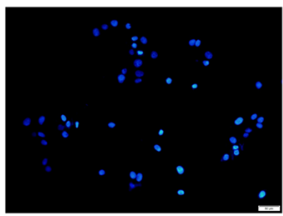

$20 \mu \mathrm{M}$ luteolin

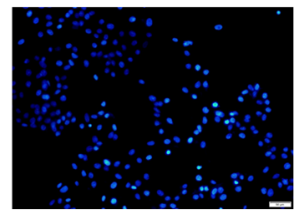

$10 \mu \mathrm{M}$ luteolin

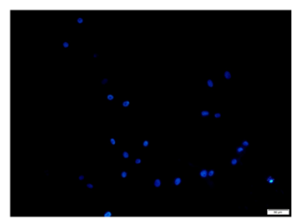

$40 \mu \mathrm{M}$ luteolin

Fig. 4. Luteolin inhibits lung cancer cell invasion. (A) The percentage of invaded cells/field were measured. (B) The cell invasion was observed by using Hoechst 33342 staining $($ scale bar $=100 \mu \mathrm{m})$. Data are expressed as mean \pm SEM from four independent experiments. The differences between groups were evaluated by one-way ANOVA. ${ }^{*}<0.001$ compared to control.

(A)
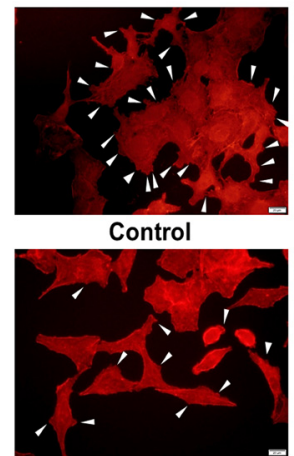

$20 \mu \mathrm{M}$ luteolin

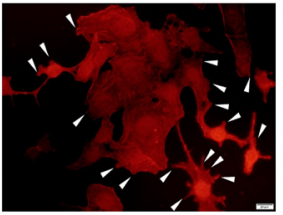

$10 \mu \mathrm{M}$ luteolin

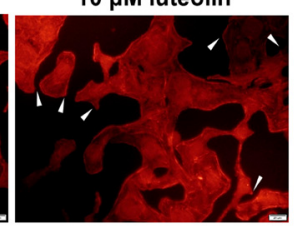

$40 \mu \mathrm{M}$ luteolin
(B)

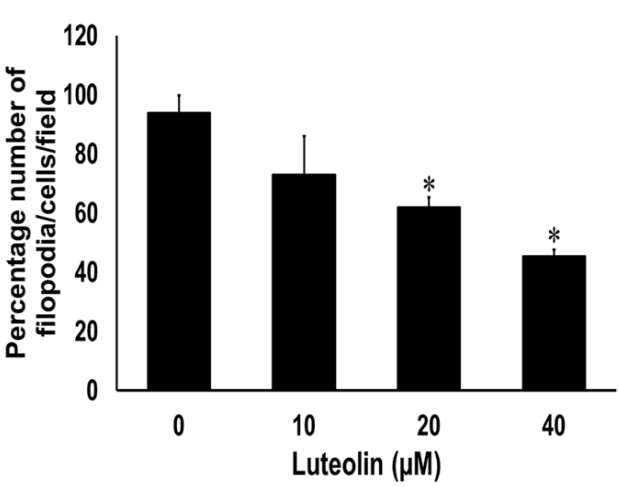

Fig. 5. Effects of luteolin on filopodia formation. (A) A549 cells were stained with phalloidin-rhodamine (scale bar $=50 \mu \mathrm{m}$ ). White arrowheads indicate the filopodia. (B) Filopodia counts per cell after treatment with various concentrations of luteolin. Data are expressed as mean \pm SEM from four independent experiments. The differences between groups were evaluated by one-way ANOVA ${ }^{*} P<0.001$ compared to control.

the migration of cell across the wound space at 24 and $48 \mathrm{~h}$, compared to the untreated control. We further determined the anti-invasive activity of luteolin against A549 cells. Our results indicated that luteolin at the concentrations 10,20 and $40 \mu \mathrm{M}$ was able to significantly diminish the invading cells across the matrix and transwell membrane at $24 \mathrm{~h}$, in a concentrationdependent manner, compared to the untreated control (Fig. $4 \mathrm{~A}$ and $4 \mathrm{~B})$.
Luteolin attenuates filopodia formation of lung cancer A549 cells

The cellular protrusions known as filopodia are a principal marker of motile cells. Cancer cells display formation of filopodia during migration and invasion $[5,26]$. Accordingly, we observed the numbers of filopodia formed for response to luteolin treatment. The A549 cells were administered with various concentrations of luteolin $(0-40 \mu \mathrm{M})$ for $24 \mathrm{~h}$, after which phalloidin-rhodamine staining assay was used to evaluate the 
(A)

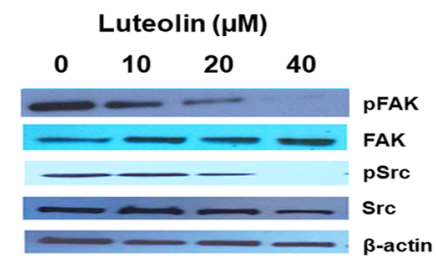

(B)

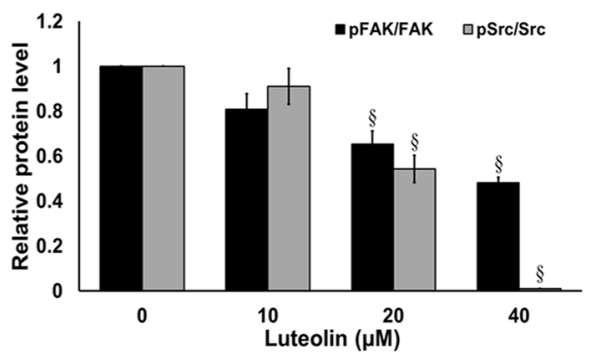

(C)

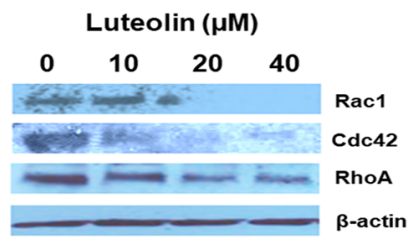

(D)

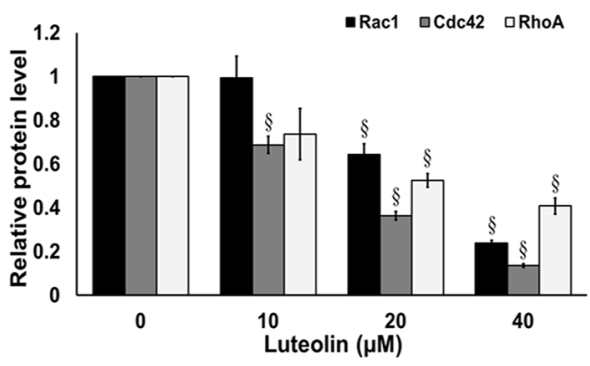

Fig. 6. Luteolin inhibits focal adhesion kinase (FAK), non-receptor tyrosine kinase ( $\mathrm{Src}$ ), Ras-related C3 botulinum toxin substrate 1 (Rac1), cell division control protein 42 (Cdc42), and Ras homolog gene family member A (RhoA) protein expressions. (A) and (B) Western blots and the relative level of FAK and Src in A549 cells after treatment with luteolin for $24 \mathrm{~h}$. (C) and (D) Western blots and the relative level of Rac1, Cdc42 and RhoA in A549 cells after treatment with luteolin for $24 \mathrm{~h}$. Data are shown as mean \pm SEM from four independent experiments, ${ }^{\S} P<0.01$ compared to control.

production of filopodia. Fig. 5A and 5B show that A549 cells treated with luteolin exhibited significantly reduced numbers of filopodia in a concentration-dependent manner, when compared to the untreated control.

\section{Luteolin suppresses migration-related protein expression in lung cancer A549 cells}

To clarify the mechanisms by which luteolin suppressed the cancer migration and invasion of cell, the expression levels of proteins associated with cell migration were assessed. The A549 cells were exposed with or without luteolin (10-40 $\mu \mathrm{M})$ for 24 h. Protein expression of FAK, activated FAK (phosphorylated FAK at Tyr-397), Src, and activated Src (phosphorylated Src at Ser416), were investigated from western blots. Fig. $6 A$ and $6 B$ shows that treatment of A549 cells with luteolin $(20-40 \mu \mathrm{M})$ substantially suppressed the expression of activated FAK and activated Src, while the non-activated forms of FAK and Src proteins were not affected. Moreover, the expression levels of Rac1, Cdc42 and RhoA were tightly related to cancer cell migration. We further evaluated at the protein levels by examined the expression of Rac1, Cdc42 and RhoA. The results show that luteolin (20-40 $\mathrm{MM}$ ) significantly down-regulated Rac1, Cdc42 and RhoA expression in A549 non-small cell lung cancer cells (Fig. 6C and 6D). These results imply that luteolin possibly regulated cell migration by suppressing FAK and Src upstream pathways, and Rac1, Cdc42 and RhoA downstream pathway.

\section{DISCUSSION}

Flavonoids, such as luteolin, have shown potential to be developed to anticancer treatments [27]. Luteolin, 3,4,5,7tetrahydroxy flavone, has been noted to have a strong anticancer effect against lung cancer cells $[21,22]$. In order to obtain further information concerning the anti-cancer activities of luteolin compound, its suppressive activity on the cancer cells migration and invasion were investigated in this study. Previous studies have reported that luteolin possesses cytotoxic efficacy against many human cancer cell lines, including esophageal carcinoma EC1 and KYSE450 cell lines, human gastric cancer MKN45 and BGC823 cell lines, human cervical cancer HeLa cell line, and human lung carcinoma $\mathrm{H} 520$ and $\mathrm{H} 661$ cell lines, with the respective $\mathrm{IC}_{50}$ values at $24 \mathrm{~h}$ ranging from 5 to $80 \mu \mathrm{M}$ [28-30]. In this study, we determined the cytotoxic properties of luteolin on human non-small cell lung cancer (NSCLC) A549 cells, and found that luteolin has an $\mathrm{IC}_{50}$ of $78.86 \mu \mathrm{M}$ at $24 \mathrm{~h}$, while it did not show substantial toxicity against normal human lung fibroblast MRC-5 cells.

Lung cancer is among primary causes of cancer-associated mortality worldwide, in both men and women, partly because of active metastasis by transmiting malignant cells to other parts of the body [31]. Among multiple processes involved in metastasis, cancer cell migration has been identified as a critical indication of metastasis throughout the body [31]. Several studies reported the anti-migration and anti-invasion potentials of luteolin on breast cancer and glioblastoma cell lines [21,32]. Also, the suppression of migration and invasion by luteolin has been evaluated in lung cancer cells [21] but the mechanisms still undefined. This present study demonstrated that luteolin significantly blocked lung cancer cells' migration and invasion in a concentration-dependent manner. Therefore, our results illustrate that luteolin inhibits the invasion and migration of A549 cells by hindering filopodia formation, and down-regulating the expression of focal adhesion kinase (FAK)-non-receptor tyrosine kinase (Src) signaling cascade in motility down-stream regulator proteins, including Ras-related C3 botulinum toxin substrate 1 (Rac1), cell division control protein 42 (Cdc42), and Ras homolog gene family member A (RhoA).

A recent study demonstrated the FAK/Src signaling as a target pathway to inhibit for preventing cancer metastasis [12]. Additionally, the expression levels of FAK and Src were reported to be upregulated in NSCLC tissues, when compared with normal lung tissue, and strongly correlated with metastatic 
stage of the disease [33-35]. The dual kinase complex FAK-Src negotiated signaling pathway is the remarkably critical signaling pathways related to metastasis from many tumors types [36-38]. FAK phosphorylation at Y397 is important for its stimulation and Src recruitment [39] and critical for cell migration [40,41]. It has also been reported that luteolin diminished the phosphorylation of FAK at Y397 and decreased phosphorylated Src at Y416 in lung cancer A549 cell lines, while Y416 phosphorylation preserves Src in an active form and stimulates Src enlistment to FAK $[42,43]$. Recent studies have established FAK-Src signaling deregulation in many tumor types $[12,42]$. Lung tumors with increased activity of FAK and Src have also increased metastatic potential [34,35]. Consequently, the suppression of FAK-Src signaling by luteolin may decrease the ability of lung cancer cells to migrate and invade.

The migration of cells is mainly forced by F-actin polymerization, focal adhesion complexes' development at the leading border, depolymerization of F-actin, and focal adhesion complexes' disassembly at the rear end of the cell [44]. The formation of cellular protrusions is an important step in triggering cell motility $[5,26]$. FAK-Src possesses the capacity to mediate transformations of the cell, including uncontrolled cell division, and it stimulates several downstream targets such as Rac1, Cdc42 and RhoA pathways $[26,45,46]$. Our results show that luteolin inhibits filopodia formation and correlates with the protein expression inhibition of downstream signaling pathways (Rac1, Cdc42 and RhoA) in A549 cells. RhoA involves cell to cell or cell to extracellular matrix communication by activating the changes of cytoskeleton. Rac1 affects membrane ruffling by changing the polymerization of actin and Cdc42, involved in the development of filopodia, via triggering assembly of F-actin filaments. In this study, we demonstrated that luteolin reduced the quantity of F-actin fibers and disturbed development of the long stress fiber that traverses the cell body. This modification in actin cytoskeleton is likely associated with diminished migration and invasion, which correlated with down-regulated expression of RhoA, Rac1, and Cdc42. This might damage the contraction and retraction of cell body at the rear end of the cell, and restrict development of protrusions at the leading border.

In conclusion, luteolin treatment restrict the migration of non-small cell lung cancer cells in vitro by abolishing the development of focal adhesion, and by inhibiting FAK-Src signaling. Luteolin also changes the expression of Rac1, Cdc42 and RhoA that are regulating proteins of actin cytoskeleton and of cell migration (Fig. 7). Further investigations are needed to validate our conclusion in an animal study and to develop luteolin for lung cancer chemotherapeutic application. Overall, luteolin appears a promising candidate for ancillary treatment to prevent tumor cell metastasis.

\section{ACKNOWLEDGMENTS}

The study was supported by the grant from the General Project and Invention of Prince of Songkla University (no. SCl610456S) and Faculty of Science Research Fund (Contract no. 1-2560-02-004), Prince of Songkla University, Songkhla, Thailand. The authors are thankful for Publication Clinic of Prince of Songkla University and Associate Professor Seppo
Karrila, Ph.D. for providing assistance in proofreading on the manuscript.

\section{CONFLICT OF INTEREST}

The authors declare no potential conflicts of interests.

\section{ORCID}

Wuttipong Masraksa: https://orcid.org/0000-0002-6183-5429

Supita Tanasawet: https://orcid.org/0000-0002-6877-9298

Pilaiwanwadee Hutamekalin: https://orcid.org/0000-0003-2892 $-7003$

Tulaporn Wonhtawatchai: https://orcid.org/0000-0002-36096740

Wanida Sukketsiri: https://orcid.org/0000-0003-0836-1487

\section{REFERENCES}

1. Bray F, Ferlay J, Soerjomataram I, Siegel RL, Torre LA, Jemal A. Global cancer statistics 2018: GLOBOCAN estimates of incidence and mortality worldwide for 36 cancers in 185 countries. CA Cancer J Clin 2018;68:394-424.

2. Sher T, Dy GK, Adjei AA. Small cell lung cancer. Mayo Clin Proc 2008;83:355-67.

3. Artal Cortés Á, Calera Urquizu L, Hernando Cubero J. Adjuvant chemotherapy in non-small cell lung cancer: state-of-the-art. Transl Lung Cancer Res 2015;4:191-7.

4. Hall A. Rho GTPases and the actin cytoskeleton. Science 1998;279: 509-14.

5. Ridley AJ. Rho GTPases and cell migration. J Cell Sci 2001;114: 2713-22.

6. Iden S, Collard JG. Crosstalk between small GTPases and polarity proteins in cell polarization. Nat Rev Mol Cell Biol 2008;9:846-59.

7. Tomar A, Schlaepfer DD. Focal adhesion kinase: switching between GAPs and GEFs in the regulation of cell motility. Curr Opin Cell Biol 2009;21:676-83.

8. Lee BY, Timpson P, Horvath LG, Daly RJ. FAK signaling in human cancer as a target for therapeutics. Pharmacol Ther 2015;146:132-49.

9. Yeatman TJ. A renaissance for SRC. Nat Rev Cancer 2004;4:470-80.

10. Zhang S, Yu D. Targeting Src family kinases in anti-cancer therapies: turning promise into triumph. Trends Pharmacol Sci 2012;33:122-8.

11. Park GB, Kim D. Cigarette smoke-induced EGFR activation promotes epithelial mesenchymal migration of human retinal pigment epithelial cells through regulation of the FAK-mediated Syk/Src pathway. Mol Med Rep 2018;17:3563-74.

12. Mitra SK, Schlaepfer DD. Integrin-regulated FAK-Src signaling in normal and cancer cells. Curr Opin Cell Biol 2006;18:516-23.

13. Prateep A, Sumkhemthong $S$, Karnsomwan W, De-Eknamkul W, Chamni S, Chanvorachote P, Chaotham C. Avicequinone B sensitizes anoikis in human lung cancer cells. J Biomed Sci 2018;25:32.

14. Miean KH, Mohamed S. Flavonoid (myricetin, quercetin, kaempferol, luteolin, and apigenin) content of edible tropical plants. J Agric Food Chem 2001;49:3106-12.

15. Imran $M$, Rauf $A$, Abu-Izneid $T$, Nadeem $M$, Shariati $M A$, Khan IA, Imran A, Orhan IE, Rizwan M, Atif M, Gondal TA, Mubarak MS. Luteolin, a flavonoid, as an anticancer agent: a review. Biomed Pharmacother 2019;112:108612. 
16. López-Lázaro M. Distribution and biological activities of the flavonoid luteolin. Mini Rev Med Chem 2009;9:31-59.

17. Xu T, Li D, Jiang D. Targeting cell signaling and apoptotic pathways by luteolin: cardioprotective role in rat cardiomyocytes following ischemia/reperfusion. Nutrients 2012;4:2008-19.

18. Birt DF, Hendrich S, Wang W. Dietary agents in cancer prevention: flavonoids and isoflavonoids. Pharmacol Ther 2001;90:157-77.

19. Martin KR. Targeting apoptosis with dietary bioactive agents. Exp Biol Med (Maywood) 2006;231:117-29.

20. Rauf A, Imran M, Butt MS, Nadeem M, Peters DG, Mubarak MS. Resveratrol as an anti-cancer agent: a review. Crit Rev Food Sci Nutr 2018;58:1428-47.

21. Chen KC, Chen CY, Lin CR, Yang TY, Chen TH, Wu LC, Wu CC. Luteolin attenuates TGF- $\beta 1$-induced epithelial-mesenchymal transition of lung cancer cells by interfering in the PI3K/Akt-NF-KB-Snail pathway. Life Sci 2013;93:924-33.

22. Ma L, Peng H, Li K, Zhao R, Li L, Yu Y, Wang X, Han Z. Luteolin exerts an anticancer effect on $\mathrm{NCl}-\mathrm{H} 460$ human non-small cell lung cancer cells through the induction of Sirt1-mediated apoptosis. Mol Med Rep 2015;12:4196-202.

23. Wang $Q$, Wang $H$, Jia $Y$, Ding $H$, Zhang L, Pan $H$. Luteolin reduces migration of human glioblastoma cell lines via inhibition of the p-IGF-1R/PI3K/AKT/mTOR signaling pathway. Oncol Lett 2017;14: 3545-51.

24. Sukketsiri W, Sawangjaroen K, Tanasawet S. Anti-apoptotic effects of phyllanthin against alcohol induced liver cell death. Trop J Pharm Res 2016;5:981-8.

25. Singkhorn S, Tantisira MH, Tanasawet S, Hutamekalin P, Wongtawatchai $\mathrm{T}$, Sukketsiri W. Induction of keratinocyte migration by ECa 233 is mediated through FAK/Akt, ERK, and p38 MAPK signaling. Phytother Res 2018;32:1397-403.

26. Sit ST, Manser E. Rho GTPases and their role in organizing the actin cytoskeleton. J Cell Sci 2011;124:679-83.

27. Lin Y, Shi R, Wang X, Shen HM. Luteolin, a flavonoid with potential for cancer prevention and therapy. Curr Cancer Drug Targets 2008;8:634-46.

28. Chen $P$, Zhang JY, Sha BB, Ma YE, Hu T, Ma YC, Sun H, Shi JX, Dong ZM, Li P. Luteolin inhibits cell proliferation and induces cell apoptosis via down-regulation of mitochondrial membrane potential in esophageal carcinoma cells EC1 and KYSE450. Oncotarget 2017:8:27471-80.

29. Cherng JM, Shieh DE, Chiang W, Chang MY, Chiang LC. Chemopreventive effects of minor dietary constituents in common foods on human cancer cells. Biosci Biotechnol Biochem 2007;71:1500-4.

30. Pu Y, Zhang T, Wang J, Mao Z, Duan B, Long Y, Xue F, Liu D, Liu $S$, Gao Z. Luteolin exerts an anticancer effect on gastric cancer cells through multiple signaling pathways and regulating miRNAs. J Cancer 2018;9:3669-75.

31. Molina JR, Yang P, Cassivi SD, Schild SE, Adjei AA. Non-small cell lung cancer: epidemiology, risk factors, treatment, and survivorship. Mayo Clin Proc 2008;83:584-94.

32. Cook MT. Mechanism of metastasis suppression by luteolin in breast cancer. Breast Cancer (Dove Med Press) 2018;10:89-100.

33. Carelli S, Zadra G, Vaira V, Falleni M, Bottiglieri L, Nosotti M, Di Giulio AM, Gorio A, Bosari S. Up-regulation of focal adhesion kinase in non-small cell lung cancer. Lung Cancer 2006;53:263-71.

34. Ji HF, Pang D, Fu SB, Jin Y, Yao L, Qi JP, Bai J. Overexpression of focal adhesion kinase correlates with increased lymph node metastasis and poor prognosis in non-small-cell lung cancer. J Cancer Res Clin Oncol 2013;139:429-35.

35. Mazurenko NN, Kogan EA, Zborovskaya IB, Kisseljov FL. Expression of pp60c-src in human small cell and non-small cell lung carcinomas. Eur J Cancer 1992;28:372-7.

36. Bolós V, Gasent JM, López-Tarruella S, Grande E. The dual kinase complex FAK-Src as a promising therapeutic target in cancer. Onco Targets Ther 2010;3:83-97.

37. Carragher NO, Frame MC. Focal adhesion and actin dynamics: a place where kinases and proteases meet to promote invasion. Trends Cell Biol 2004;14:241-9.

38. Gu MM, Gao D, Yao PA, Yu L, Yang XD, Xing CG, Zhou J, Shang ZF, Li M. p53-inducible gene 3 promotes cell migration and invasion by activating the FAK/Src pathway in lung adenocarcinoma. Cancer Sci 2018;109:3783-93.

39. Schaller MD, Hildebrand JD, Shannon JD, Fox JW, Vines RR, Parsons JT. Autophosphorylation of the focal adhesion kinase, pp125FAK, directs SH2-dependent binding of pp60src. Mol Cell Biol 1994;14: 1680-8

40. Chen M, Chen SC, Pallen CJ. Integrin-induced tyrosine phosphorylation of protein-tyrosine phosphatase-alpha is required for cytoskeletal reorganization and cell migration. J Biol Chem 2006; 281:11972-80.

41. Hsia DA, Mitra SK, Hauck CR, Streblow DN, Nelson JA, llic D, Huang S, Li E, Nemerow GR, Leng J, Spencer KS, Cheresh DA, Schlaepfer DD. Differential regulation of cell motility and invasion by FAK. J Cell Biol 2003;160:753-67.

42. Chikara S, Lindsey K, Borowicz P, Christofidou-Solomidou M, Reindl $\mathrm{KM}$. Enterolactone alters FAK-Src signaling and suppresses migration and invasion of lung cancer cell lines. BMC Complement Altern Med 2017; $17: 30$.

43. Sandilands E, Frame MC. Endosomal trafficking of Src tyrosine kinase. Trends Cell Biol 2008;18:322-9.

44. Gardel ML, Schneider IC, Aratyn-Schaus Y, Waterman CM. Mechanical integration of actin and adhesion dynamics in cell migration. Annu Rev Cell Dev Biol 2010;26:315-33.

45. Kim LC, Song L, Haura EB. Src kinases as therapeutic targets for cancer. Nat Rev Clin Oncol 2009;6:587-95.

46. Summy JM, Gallick GE. Src family kinases in tumor progression and metastasis. Cancer Metastasis Rev 2003;22:337-58. 